\title{
Comparative study between usage of topical azithromycin versus conventional therapy in treatment of posterior blepharitis causing dry eye
}

\author{
Abdullah Hussein Hamed, Hassan Metwally Bayoumi, Maged Muhammad \\ Mokhtar Morad* \\ Ophthalmology Department, Faculty of Medicine, Al-Azhar University \\ * Corresponding Author: Maged Muhammad Mokhtar Morad, E-mail: quiet_fighter@yahoo.com
}

\begin{abstract}
Background: blepharitis is an inflammatory condition of the eyelid that is usually associated with bacterial infection or some skin conditions (such as dandruff on the scalp, or acne rosacea). Aim of the Work: this study aimed to compare the outcome of using topical azithromycin and conventional therapy in improving signs and symptoms of posterior blepharitis causing dry eye.Patients and Methods: this comparative study was done between usage of conventional therapy and topical azithromycin in treatment of posterior blepharitis causing dry eye. One hundred and twenty eyes of sixty patients of both sexes above age of 18 diagnosed with posterior blepharitis causing dry eye disease are recruited from the ophthalmological clinic of Al-Azhar university Hospitals. Results: the azithromycin group showed a significant improvement of sign, symptoms and investigations over the conventional group in the $2^{\text {nd }}$ visit (after 1 week) while, there was a non significance regarding the $3^{\text {rd }}$ visit after one month of treatment and $3^{\text {rd }}$ after one month of stoppage of treatment. Conclusion: conventional therapy and topical azithromycin are effective on posterior blepharitis causing dry eye disease, azithromycin has more compliance and better tolerability to the patients with sustained effect on the ocular tissue that give it a preference over the conventional therapy.
\end{abstract}

Keywords: topical azithromycin, conventional therapy, posterior blepharitis causing dry eye

\section{Introduction}

Blepharitis is an inflammatory condition of the eyelid that is usually associated with bacterial infection or some skin conditions (such as dandruff on the scalp, or acne rosacea) (1). Blepharitis can be classified in several different ways: first one based on the length of disease process: acute or chronic blepharitis. Second classification was based on the anatomical location of the disease: Anterior blepharitis affects the eyelid skin, base of the eyelashes and the eyelash follicles and included the traditional classifications of staphylococcal and seborrheic blepharitisand posterior blepharitis that affects the Meibomian glands and gland orifices ${ }^{(2)}$. Meibomian glands are a modified, holocrine, sebaceous glands that are embedded in the tarsal plate of the both the upper and lower eyelid and excrete lipid onto the surface of the eye to form the lipid layer of the tear film to reduce aqueous tear evaporation. Dysfunction of the Meibomian gland (MGD) is a common eyelid condition which is responsible for developing evaporative dry eye (3). There are several proposed theories on the etiology of this obstruction. One theory suggested that Meibomian gland dysfunction is the result of hyperkeratinisation of the epithelium lining the MG ducts, while another theory suggested that the changes were occurring in the MG secretions or the meibum. Once obstruction occurs, the lipid composition of the meibum becomes altered. Alterations included thickening of the secretions, increased melting point of the secretions, ductal stagnation and pouting of the MG orifices. Bacterial colonisation and inflammatory mediators are released when the meibomian glands become obstructed. The inflammatory mediators are formed when lipolytic enzymes that are produced from bacteria, such as Staphylococcus epidermidis, Staphylococcus aureus, Propionibacterium acnes and Cornebacterium. The lipolytic enzymes released by the bacteria result in highly irritating free fatty acids that compromise the tear film integrity. Both the structural changes to the MG and the secretions contribute to increased evaporation of the tear film, increased tear osmolarity and increased inflammatory cytokines that ultimately damage the ocular surface, resulting in patient symptoms and development of that condition ${ }^{(4,3)}$. Clinical symptoms include burning, grittiness, dryness, foreign body sensation, redness, crusty and 
heavy eyelid which increase especially at morning and fluctuating vision. While clinical signs include lid margin hyperemia, plugging or inspissation of $\mathrm{MG}$ orifices, abnormal thickened meibomian gland secretions, foamy tears, tear film debris ${ }^{(5)}$. Blepharitis can be treated either with conventional therapy of meibomian gland dysfunction includes mechanical options of lid hygiene, massage and expression and warm compresses as well as medicinal therapy of systemic tetracycline and doxycycline, but such therapeutic measures are often unsatisfactory or not well tolerated (ब).Clinical trials had identified topical azithromycin as an effective and well tolerated therapy of lid margin disease and meibomian gland dysfunction. Azithromycin is antiinflammatory inhibiting proinflammatory cytokines and is a potent against gram-negative microorgansims. It is believed that it has the ability to penetrate into the ocular surface where it remains at therapeutic levels into the ocular suface after the therapy has stopped ${ }^{(6,7)}$.

\section{Aim of the work}

This study aimed to compare the outcome of using topical azithromycin and conventional therapy in improving signs and symptoms of posterior blepharitis causing dry eye.

\section{Patients and method}

This was a comparative study between usage of conventional therapy and topical azithromycin in treatment of posterior blepharitis causing dry eye.

\section{Patients}

One hundred and twenty eyes of sixty patients of both sexes above age of 18 diagnosed with posterior blepharitis that causedg dry eye disease are recruited from the Ophthalmological Clinic of Al-Azhar University Hospitals. The study was approved by the Ethics Board of Al-Azhar University.

\section{The sixty patients were categorized into two groups:}

1. Group A: thirty patients underwent conventional therapy with administration of an oral doxycycline $100 \mathrm{mg}$ per day for 1 month in addition to lid hygiene at bedtime with baby shampoo, and warm compresses two times per day each one is 5 minutes.

No lubricant eye drops were used by the patients during the study period because their use would affect the tear break-up time (TBUT) and Schirmer's test results

2. Group B: thirty patients applied topical azithromycin $1 \%$ four times per day for one month.

\section{Patient with this criteria were excluded:}

1. Patient younger than 18 years of age.

2. Pregnant or lactating mother.

3. Lid structural abnormalities, inflammatory or infectious keratitis or uveitis, penetrating intraocular surgery during the past three months, ocular surface surgery (such as LASIK and pterygiectomy) in the past six months.

4. A known hypersensitivity to azithromycin or doxycycline, and the use of any of the following medications within one month of the study: topical or oral antibiotics, topical or systemic steroids,topical nonsteroidal anti-inflammatory drugs, topical cyclosporine and topical antihistamine and/or mast cell stabilizers.

5. Patient use any topical or systemic medication in treatment of meibmoian gland dysfunction such as steroid.

\section{Method}

All patients had been subjected to:

- Full history taking (personal, present, past, and family history)

- Clinical examination (full ophthalmological examination)

- Ocular surface investigations like schirmer 1 paper test, rose Bengal staining, tears break-up time test.

Personal history was included (Age, sex, occupation, residence and special habits). History of present illness included the onset, course and duration of the disease and predisposing factors.

The past history included history of similar condition, previous medications, and systemic diseases.

Full ophthalmic examination included: visual acuity and BCVA, slit lamp examination. Study design

The study was prospective randomized intra-individual comparative clinical trial.

The disease was graded by symptoms as the patients say supported by their history, and by signs observed by ophthalmic examination, then finally Schirmer paper, rose Bengal staining, and tears break-up time test were done. 
Symptoms were included: foreign body sensation, lacrimation, itching, burning sensation and vision fluctuation.

At baseline and at the follow-up visits, patients were asked to fill out a questionnaire to grade their subjective symptoms. The sum of these four symptoms was recorded as total symptom score at each visit.

\section{Statistical analysis}

Data were collected, revised, coded and entered to the Statistical Package for Social Science (IBM SPSS) version 23. The quantitative data were presented as mean, standard deviations and ranges. Also qualitative variables were presented as number and percentages. So, the p-value was considered significant as the following: $\mathrm{P}>0.05$ : Non significant (NS), P < 0.05: Significant (S), P < 0.01: Highly significant (HS).

\section{Results}

Table 1: comparison between age and sex in the 2 groups

\begin{tabular}{|c|c|c|c|c|c|c|}
\hline & Azithromycin group & Conventional group & \multirow{2}{*}{ Test value } & \multirow{2}{*}{ P-value } & \multirow{2}{*}{ Sig. } \\
\hline & & No. $=30$ & No. $=30$ & & & \\
\hline Age & $\begin{array}{l}\text { Mean } \pm \text { SD } \\
\text { Range }\end{array}$ & $\begin{array}{c}44.20 \pm 12.59 \\
27-68\end{array}$ & $\begin{array}{c}44.10 \pm 10.29 \\
24-65\end{array}$ & $0.034 \bullet$ & 0.973 & NS \\
\hline Sex & $\begin{array}{l}\text { Females } \\
\text { Males }\end{array}$ & $\begin{array}{l}15(50.0 \%) \\
15(50.0 \%)\end{array}$ & $\begin{array}{l}16(53.3 \%) \\
14(46.7 \%)\end{array}$ & $0.067 *$ & 0.796 & NS \\
\hline
\end{tabular}

The age of the patients ranged from 27 to 68 years considering group A with 15 patient (50\%) female and 15 patient male (50\%). The age of the other group range from 24 to 65 years with 16 patients $(53.3 \%)$ were female and 14 patients $(47.7 \%)$ were male.

Table 2: comparison between the 2 groups at the $2^{\text {nd }}$ visit regarding the symptoms

\begin{tabular}{|c|c|c|c|c|c|c|}
\hline \multirow{2}{*}{\multicolumn{2}{|c|}{ Second Visit }} & Azithromycin group & Conventional group & \multirow{3}{*}{ Test value• } & \multirow{2}{*}{ P-value } & \multirow{2}{*}{ Sig. } \\
\hline & & \multirow[t]{2}{*}{ No. $=30$} & \multirow[t]{2}{*}{ No. $=30$} & & & \\
\hline Symptoms & & & & & & \\
\hline Foreign body sensation & $\begin{array}{l}\text { Mean } \pm \text { SD } \\
\text { Range }\end{array}$ & $\begin{array}{c}1.47 \pm 0.73 \\
0-3\end{array}$ & $\begin{array}{c}1.73 \pm 0.69 \\
0-3\end{array}$ & -1.452 & 0.152 & NS \\
\hline Lacrimation & $\begin{array}{l}\text { Mean } \pm \text { SD } \\
\text { Range }\end{array}$ & $\begin{array}{c}1.0 \pm 0.79 \\
0-3\end{array}$ & $\begin{array}{c}1.43 \pm 0.77 \\
0-3\end{array}$ & -2.149 & 0.036 & $S$ \\
\hline Burning & $\begin{array}{l}\text { Mean } \pm \text { SD } \\
\text { Range }\end{array}$ & $\begin{array}{c}1.40 \pm 0.72 \\
0-2\end{array}$ & $\begin{array}{c}1.63 \pm 0.81 \\
0-3\end{array}$ & -1.177 & 0.244 & NS \\
\hline Itching & $\begin{array}{l}\text { Mean } \pm \text { SD } \\
\text { Range }\end{array}$ & $\begin{array}{c}1.40 \pm 0.56 \\
1-3\end{array}$ & $\begin{array}{c}1.80 \pm 0.76 \\
0-3\end{array}$ & -2.314 & 0.024 & $S$ \\
\hline Vision fluctuation & $\begin{array}{l}\text { Mean } \pm \text { SD } \\
\text { Range }\end{array}$ & $\begin{array}{c}0.63 \pm 0.61 \\
0-2\end{array}$ & $\begin{array}{c}0.97 \pm 0.67 \\
0-2\end{array}$ & -2.010 & 0.049 & S \\
\hline
\end{tabular}

Symptoms showed a significant difference between azithromycin group and conventional group in lacrimation, itching and vision fluctuation, whereas the burning sensation and foreign body sensation show non-significant difference.

Table 3: comparison between both groups at the $2^{\text {nd }}$ visit regarding signs

\begin{tabular}{|c|c|c|c|c|c|c|}
\hline \multirow{2}{*}{\multicolumn{2}{|c|}{ Second Visit }} & \multirow{2}{*}{$\begin{array}{c}\text { Azithromycin group } \\
\text { No. }=30\end{array}$} & \multirow{2}{*}{$\begin{array}{c}\text { Conventional group } \\
\text { No. }=\mathbf{3 0}\end{array}$} & \multirow{2}{*}{ Test value• } & \multirow{2}{*}{ P-value } & \multirow{2}{*}{ Sig. } \\
\hline & & & & & & \\
\hline \multicolumn{7}{|l|}{ Signs } \\
\hline Lid hyperemia & $\begin{array}{l}\text { Mean } \pm \text { SD } \\
\text { Range }\end{array}$ & $\begin{array}{c}1.60 \pm 0.89 \\
0-3\end{array}$ & $\begin{array}{c}2.10 \pm 0.55 \\
1-3\end{array}$ & -2.611 & 0.011 & $S$ \\
\hline Lid collarettes & $\begin{array}{l}\text { Mean } \pm \text { SD } \\
\text { Range }\end{array}$ & $\begin{array}{c}0.80 \pm 0.84 \\
0-3\end{array}$ & $\begin{array}{c}1.07 \pm 0.69 \\
0-3\end{array}$ & -1.336 & 0.187 & NS \\
\hline MG secretion & \begin{tabular}{|l} 
Mean \pm SD \\
Range
\end{tabular} & $\begin{array}{c}1.83 \pm 0.70 \\
1-3\end{array}$ & $\begin{array}{c}2.03 \pm 0.56 \\
1-3\end{array}$ & 1.227 & 0.225 & NS \\
\hline Conjunctival hyperemia & $\begin{array}{l}\text { Mean } \pm \text { SD } \\
\text { Range }\end{array}$ & $\begin{array}{c}1.10 \pm 0.88 \\
0-3\end{array}$ & $\begin{array}{c}1.57 \pm 0.73 \\
0-3\end{array}$ & -2.231 & 0.030 & $S$ \\
\hline Frothy discharge & $\begin{array}{l}\text { Mean } \pm \text { SD } \\
\text { Range }\end{array}$ & $\begin{array}{c}1.50 \pm 0.73 \\
0-3\end{array}$ & $\begin{array}{c}1.40 \pm 0.67 \\
1-3\end{array}$ & 0.551 & 0.584 & NS \\
\hline
\end{tabular}

The signs of $2^{\text {nd }}$ visit showed a significant difference between azithromycin group and conventional therapy group in eyelid and conjunctival hyperermia, while non-significant difference in meibomian gland secretion, frothy discharge and lid collarettes.

Table 4: comparison between both groups at the $2^{\text {nd }}$ visit regarding the investigations 
Comparative study between usage of topical azithromycin versus conventional therapy...

\begin{tabular}{|c|c|c|c|c|c|c|}
\hline \multirow{2}{*}{\multicolumn{2}{|c|}{ Second Visit }} & Azithromycin group & Conventional group & \multirow{3}{*}{ Test value• } & \multirow{3}{*}{ P-value } & \multirow{3}{*}{ Sig. } \\
\hline & & \multirow{2}{*}{ No. $=\mathbf{3 0}$} & \multirow[t]{2}{*}{ No. $=30$} & & & \\
\hline Investigations & & & & & & \\
\hline TBUT & $\begin{array}{l}\text { Mean } \pm \text { SD } \\
\text { Range }\end{array}$ & $\begin{array}{c}6.13 \pm 1.33 \\
4-10\end{array}$ & $\begin{array}{c}5.23 \pm 1.41 \\
2-8\end{array}$ & 2.545 & 0.014 & S \\
\hline ROSE Bengal stain & $\begin{array}{l}\text { Mean } \pm S D \\
\text { Range }\end{array}$ & $\begin{array}{c}0.33 \pm 0.48 \\
0-1\end{array}$ & $\begin{array}{c}0.47 \pm 0.68 \\
0-2\end{array}$ & -0.876 & 0.384 & NS \\
\hline SCHIRMER & $\begin{array}{l}\text { Mean } \pm \text { SD } \\
\text { Range }\end{array}$ & $\begin{array}{c}8.90 \pm 1.37 \\
6-11\end{array}$ & $\begin{array}{c}8.07 \pm 1.44 \\
5-11\end{array}$ & 2.296 & 0.025 & $S$ \\
\hline
\end{tabular}

The investigations showed a significant difference in both TBUT and schirmer paper test, while at rose Bengal stain it shows no statistically difference between both groups.

Table 5: comparison between both groups at the $4^{\text {th }}$ visit regarding the investigations

\begin{tabular}{|c|c|c|c|c|c|c|}
\hline \multirow{2}{*}{\multicolumn{2}{|c|}{ Fourth Visit }} & Azithromycin group & Conventional group & \multirow{3}{*}{ Test value• } & \multirow{2}{*}{ P-value } & \multirow{2}{*}{ Sig. } \\
\hline & & No. $=\mathbf{3 0}$ & No. $=\mathbf{3 0}$ & & & \\
\hline \multicolumn{6}{|l|}{ Investigations } & \\
\hline TBUT & $\begin{array}{l}\text { Mean } \pm \text { SD } \\
\text { Range }\end{array}$ & $\begin{array}{c}8.20 \pm 1.88 \\
6-14\end{array}$ & $\begin{array}{c}7.30 \pm 1.21 \\
5-10\end{array}$ & 2.204 & 0.032 & S \\
\hline ROSE Bengal stain & \begin{tabular}{|l}
$\begin{array}{l}\text { Mean } \pm S D \\
\text { Range }\end{array}$ \\
\end{tabular} & $\begin{array}{c}0.00 \pm 0.00 \\
0-0\end{array}$ & $\begin{array}{c}0.07 \pm 0.25 \\
0-1\end{array}$ & -1.439 & 0.155 & NS \\
\hline SCHIRMER & $\begin{array}{l}\text { Mean } \pm \text { SD } \\
\text { Range }\end{array}$ & $\begin{array}{c}12.03 \pm 1.45 \\
9-14\end{array}$ & $\begin{array}{c}11.07 \pm 2.07 \\
8-15 \\
\end{array}$ & 2.097 & 0.040 & $\mathrm{~S}$ \\
\hline
\end{tabular}

Comparison showed a significant difference between azithromycin group in both TBUT and schirmer paper test and no significant difference in rose bengal stain.

Table 6: number and percentage of patients suffer from side effects during the treatment period

\begin{tabular}{|l|c|c|c|c|}
\hline \multirow{2}{*}{ Side effects } & \multicolumn{2}{c|}{ Azithromycin group } & \multicolumn{2}{c|}{ Conventional group } \\
\cline { 2 - 5 } & \multicolumn{2}{|c|}{ No. = 30 } & \multicolumn{2}{c|}{ No. = 30 } \\
\hline No & 15 & $50.0 \%$ & 12 & $40.0 \%$ \\
Burning sensation upon instillation & 9 & $30.0 \%$ & 0 & $0.0 \%$ \\
GIT upset & 0 & $0.0 \%$ & 14 & $46.7 \%$ \\
Stinging & 3 & $10.0 \%$ & 0 & $0.0 \%$ \\
Sticky eyelids & 3 & $10.0 \%$ & 0 & $0.0 \%$ \\
Photosenstivity & 0 & $0.0 \%$ & 3 & $10.0 \%$ \\
Allergic reaction & 0 & $0.0 \%$ & 1 & $3.3 \%$ \\
\hline
\end{tabular}

\section{Discussion}

Although blepharitis is a common and chronic disorder, there is no consensus on standard management. The etiology of the disorder is complex and not completely understood, but the general consensus is that bacteria and inflammation contribute to the pathology of this condition (8). Most cases usually require conservative management including warm compresses to provide appropriate meibum secretion, mechanical eyelid massage and cleansing with shampoo and cotton buds to remove excess debris from eyelid, and artificial tears to continuously lubricate the ocular surface. In severe and refractory cases, however, antibiotics (topical and/or systemic) with anti-inflammatory properties are proposed (14). Luchs (7) considered that the warm compresses applied to the closed eyelids for several minutes are a main component of treatment of blepharitis, often the clinical improvement is slow or insufficient, and show a less compliance requiring additional limited-duration or poorly tolerated therapies including systemic tetracycline antibiotics. Doxycycline is a long acting tetracycline analogue which is used in MGD through its antimicrobial, antiinflammatory and anti-metalloproteinase properties, with fewer side effects than other tetracyclines ${ }^{(\mathbf{6})}$.Azithromycin, a macrolide with a broad-spectrum antibacterial effect, and also has anti-inflammatory activities. Recent studies showed a significant improvement in the signs and symptoms caused by posterior blepharitis such as dry eye after the use of azithromycin $1 \%$ ophthalmic solution ${ }^{(9)}$. Conventional therapy of MGD included mechanical options of lid massage, lid expression and warm compresses as well as medicinal therapy of systemic tetracycline and doxycycline. This study was performed on 60 patient diagnosed with posterior blepharitis causing dry eye symptoms and signs confirmed by TBUT, schirmer paper test and rose Bengal stain, to assess and 
compare the clinical efficacy of conventional therapy and topical azithromycin. Our study was considered innovative one, as no studies had compared the efficacy of both therapies after one week of treatment and the comparison between the azithromycin alone with doxycycline, lid hygiene and warm compresses.Objective assessment and grading of the symptoms and signs was used according to the International Ocular Inflammation Society (IOIS) grading of signs and symptoms. Luchs ${ }^{(7)}$ used this system in grading symptoms ad signs. Foulks et $\boldsymbol{a l} .{ }^{(10)}$ also used this grading and scoring for symptoms and signs. This study included 30 patients in each group, the azithromycin group 15 male (50\%) and 15 female $(50 \%)$, while the doxycycline group consisted of 14 male $(46.7 \%)$ and 16 female $(53.3 \%)$. The range of age of azithromycin group was $27-68$ with the mean of the age is $44.20 \pm 12.59$, the range of the conventional group was $24-65$ and the mean of the age was $44.10 \pm 10.29$. The 2 groups showed no statistically significant difference in age and sex.Regarding the $1^{\text {st }}$ visit (after 1 week of starting treatment) the azithromycin group show significant improvement in all symptoms. The same finding was reported by Fadlallah $\boldsymbol{e t}$ al. ${ }^{(11)}$ who detected significant improvement of all symptoms after one week of treatment although he use topical azithromycin $1.5 \%$, but with lower frequency 2 times in the $1^{\text {st }} 3$ days then once daily at bed time in association with lid hygiene and warm compresses. Regarding the signs at this visit in present study show significant improvement in all signs except frothy discharge show non-significant improvement this result was consistent with those Fadlallah et al. (11) who showed improvement of lid collaret's, lid hyperemia and MG secretions.Regarding investigations: TBUT showed a significant improvement after one week of treatment with topical azithromycin. Schirmer paper test showed significant increase, but did not reach the normal value this may be because the azithromycin was not reach the therapeutic level on the meibomain gland to stabilize the tear film. Rose Bengal staining show some improvement but it was insignificant. Regarding results of conventional therapy at the $1^{\text {st }}$ visit the symptoms show non-significant improvement except in burning sensation which significantly improved due to daily cleansing of the eyelid with soothing and cleansing shampoo. Also, signs at this visit did not significantly improve except lid collaret's which also been soften with warm compresses and removed by lid hygiene. Regarding investigations at this visit the improvement was non-significant as the doxycycline did not reach the therapeutic level at the ocular tissue and improve the secretion and inflammation of the meibomain gland so stabilize the tear film. Considering the difference between both therapies the azithromycin group showed a significant improvement in lacrimation, itching and vision fluctuation, while in burning and foreign body sensation showed non-significant improvement. On the other hand the signs showed that the azithromycin group showed significantly improved conjunctival and lid hyperemia, while MG secretion, frothy discharge it showed non- significant improvement whereas lid collaret's improved with conventional therapy, but insignificantly.

Whereas the investigations showed significant improvement in azithromycin group over the conventional group in TBUT and schirmer paper test, but the rose Bengal staining was showed a non-significant difference. At the $3^{\text {rd }}$ visit (after one month of treatment) the azithromycin group was improved in all symptoms significantly this was consistent with results of Balci and Gulkilik ${ }^{(\mathbf{1 2})}$. This result is also found by Foulks et al. ${ }^{(10)}$ who stated that all symptoms improved after 4 weeks of treatment with topical azithromycin $1 \%$.Altay et al. (8) found that all symptoms were significantly improved with topical azithromycin $1.5 \%$ after one month of treatment but in lower dose one drop at bed time. This result can be explained because he use a higher concentration in association with lid hygiene and warm compresses which play a significant role in treating signs and symptoms through softer and melting the hard secretion of meibomian gland.Signs at this visit was also significantly improved as Foulks et al. (10) found after 4 weeks of treatment with topical azithromycin $1 \%$.Concerning the investigations the topical azithromycin show significant improvement in TBUT, Schirmer paper and rose Bengal staining this results are consistent with results of Altay et al. ${ }^{(8)}$ who stated that TBUT and shcirmer paper was significantly improved after one month of treatment with topical azithromycin but he did not perform rose Bengal stain. Opitz and Tyler ${ }^{(13)}$ found that TBUT, schirmer paper, corneal and 
conjunctival staining was significantly improved from baseline after one month of treatment with azithromycin. On the other hand, conventional therapy at the $3^{\text {rd }}$ visit showed a significant improvement of the symptoms and signs, this results is in consistent with results of Kashkouli et al. ${ }^{(14)}$ who found that symptoms and signs significantly improved after one month of treatment with oral doxycycline $100 \mathrm{mg}$ twice per day. This can be explained by Yoo et al. (15) who used a low dose of doxycycline $20 \mathrm{mg}$ and found that the patient after one month showed a significant improvement of signs and symptoms. They stated that although low dose doxycycline has no antimicrobial effect but it still has antiinflammatory effect that treat and improve signs and symptoms of MGD and dry eye.Our study also found that investigation significantly improved after one month of treatment.In overall, the difference between improvement by topical azithromycin group and conventional therapy was insignificant. However, the azithromycin showed better improvement in lid and conjunctival hyperemiai in consistent with Zandian et al. ${ }^{(5)}$ who found that after 3 weeks there was a significant difference between topical azithromycin and systemic doxycycline in conjunctival and lid hyperemia that was better improvement with topical azithromycin. Whereas, conventional therapy improved MG secretion and plugging more than azithromycin which also was detected by Zandian et al. ${ }^{(5)}$ with statistically significant difference.This may be explained by at 3 weeks of treatment the maximum anti-inflammatory effect of doxycycline was not reached to decrease the conjunctival or lid margin hyperemia and the doxycycline need a large time to demonstrate the maximum effect. The Schirmer paper test showed non-significant difference between both groups this was consistent with Zandian et al. ${ }^{(5)}$ who found that there was no statistical significant difference between both groups after 3 weeks of treatment in schirmer paper test. The rose Bengal staining and TBUT showed nonstatistically significant difference between both groups.

At the $4^{\text {th }}$ visit the azithromycin group showed no statistically significant difference with $3^{\text {rd }}$ visit as the improvement maintained after one month of stopping the treatment. This results are consistent with Haque et al. ${ }^{(16)}$ who found that 4 weeks after stopping treatment all symptoms and signs have no significant worsening. After one month of stopping the treatment $\left(4^{\text {th }}\right.$ visit $)$ results showed nonsignificant difference between both groups in all symptoms, signs and rose Bengal staining with the doxycycline group showed little deterioration in both signs and symptoms, while a significant difference been demonstrated in TBUT and Schirmer paper. This may explained because the azithromycin has sustained concentration on the ocular tissue even after stopping the treatment for approximately 5 weeks, while the doxycycline has not this property. As regarding the side effects the azithromycin group there was a 15 patient $(50 \%)$ of 30 patient report side effect 9 patients $(30 \%)$ reported burning sensation upon instillation but not make the patient discontinue the treatment, $3(10 \%)$ report stinging sensation, and $3(10 \%)$ reported sticky eyelid.

On the other hand, the conventional therapy group 12 patient of 30 showed no side effects during usage of oral doxycycline, while a 14 patient $(46.7 \%)$ report GIT upset including nausea, vomiting or diarrhea, another 3 patient $(10 \%)$ show some degree of photosensitivity at the end of treatment.

\section{Conclusion}

Conventional therapy and topical azithromycin are effective on posterior blepharitis causing dry eye disease, azithromycin has more compliance and better tolerability to the patients with sustained effect on the ocular tissue that give it a preference over the conventional therapy.

\section{Reference}

1. Nichols K (2010): Blepharitis and dry eye. Available in https://www.reviewofoptometry.com/a rticle/ blepharitis-and-dry-eye-acommon-yet-complicatedcombination.

2. Rahul S (2014): Blepharitis .available in http//eyewiki.aao.org/Blepharitis November 27, 2014 Cochrane Database Syst Rev., 5: CD005556.

3. James VJ, Geraint JP and Donald JB (2015): Meibomian gland dysfunction: hyperkeratinization or atrophy? BMC Ophthalmol., 15(S1): 156.

4. Fogt J, Kowalski M, King-Smith PE, Epitropoulos A, Hendershot A, Lembach C and Barr J (2016): Tear lipid layer thickness with eye drops in 
meibomian gland dysfunction. Clinical Ophthalmology, 10: 2237-2243.

5. Zandian M, Rahimian $N$ and Soheilifar $S$ (2016): Comparison of therapeutic effects of topical azithromycin solution and systemic doxycycline on posterior blepharitis. Int. J. Ophthalmol., 9(7):1016-1025

6. Foulks GN, Borchman D, Yappert $M$ and Kakar S (2013): Topical azithromycin and oral doxycycline therapy of meibomian gland dysfunction. Cornea, 32(1): 44-53.

7. Luchs J (2008): Efficacy of topical azithromycin ophthalmic solution $1 \%$ in the treatment of posterior blepharitis. Advances in Therapy, 25(9): 858-870.

8. Altay Y, Demirok G, Balta O, Bolu H (2017): RETRACTED: Azithromycin $1.5 \%$ ophthalmic solution for blepharitis Treatment: Comparison of 14- Versus 30-Day Treatment. Journal of Ocular Pharmacology and Therapeutics, 33(6): 498.

9. Yildiz E, Yenerel NM, Turan-Yardimci A, Erkan $M$ and Gunes $P$ (2018): Comparison of the clinical efficacy of topical and systemic Azithromycin treatment for posterior blepharitis. Journal of Ocular Pharmacology and Therapeutics, 34(4): 365-372.

10. Foulks GN, Borchman D, Yappert M, Kim SH, McKay JW (2010); Topical azithromycin therapy for meibomian gland dysfunction: clinical response and lipid Alterations. Cornea, 29(7): 781-788.

11. Fadlallah A, Rami HE, Fahd D, Dunia I, Bejjani R, Chlela E and Fahed S
(2012): Azithromycin $1.5 \%$

ophthalmic solution: efficacy and treatment modalities in chronic blepharitis. Arquivos Brasileiros de Oftalmologia, 75(3): 178-182.

12. Balci $O$ and Gulkilik $G$ (2018): Assessment of efficacy of topical azithromycin 1.5 per cent ophthalmic solution for the treatment of meibomian gland dysfunction. Clinical and Experimental Optometry, 101(1):18-22.

13. Opitz DL and Tyler KF (2010): Efficacy of azithromycin $1 \%$ ophthalmic solution for treatment of ocular surface disease from posterior blepharitis. Clinical and Experimental Optometry, 94(2): 200-206.

14. Kashkouli MB, Fazel AJ, Kiavash V, Nojomi $M$ and Ghiasian $L$ (2015): Oral azithromycin versus doxycycline in meibomian gland dysfunction: a randomised double-masked open-label clinical trial. British Journal of Ophthalmology, 99(2):199-204.

15. Yoo YS, Na KS, Kim DY, Yang SW, Joo CK (2017): Morphological evaluation for diagnosis of dry eye related to meibomian gland dysfunction. Experimental Eye Research, 163: 7277.

16. Haque RM, Torkildsen GL, Brubaker K, Zink RC, Kowalski RP, Mah FS and Pflugfelder SC (2010): Multicenter open-label study evaluating the Efficacy of azithromycin ophthalmic solution $1 \%$ on the signs and symptoms of Subjects with Blepharitis. Cornea, 29(8): 871-877 